(ISSN - 2752-7018)

VOLUME 02 ISSUE 01 Pages: 28-34

SJIF IMPACT FACTOR (2021: 5. 376)

OCLC -1276789625 METADATA IF -7.569

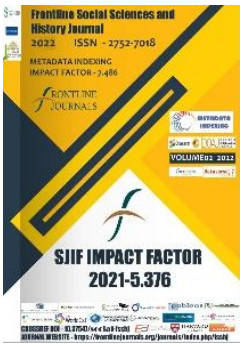

Journal Website: https://frontlinejournal s.org/journals/index.ph p/fsshj

Copyright: Original content from this work may be used under the terms of the creative commons attributes 4.0 licence.

\author{
(2) Research Article
}

\section{TEACHING PRESENTATION SKILLS TO FUTURE ENGLISH TEACHERS}

Submission Date: January 11, 2022, Accepted Date: January 21, 2022,

Published Date: January 31, 2022

Crossref doi: https://doi.org/10.37547/social-fsshj-02-01-04

Muqaddam Ibrohimova

Efl Teacher Of Namangan State University, Uzbekistan

Sevara Ziyaboyeva

Efl Teacher Of Namangan State University, Uzbekistan

\title{
Abstract
}
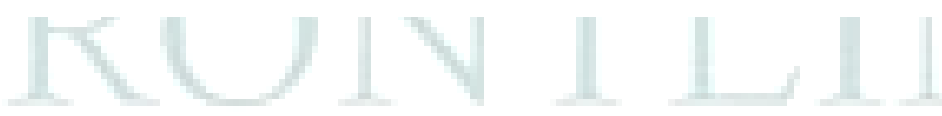

There have been a large number of scientific and methodological works published on teaching presentation skills in a foreign language. This article aims at improving presentation skills in English according to global requirements for presentation activities.

\section{KeYwordS}

Presentation, presentation skills,

\section{INTRODUCTION}


(ISSN - 2752-7018)

VOLUME 02 ISSUE 01 Pages: 28-34

SJIF IMPACT FACTOR (2021: 5 • 376)

OCLC -1276789625 METADATA IF -7.569

Today it is impossible to imagine a highly English teacher who is not able to present or who does not take part in scientific conferences to present research results, share ideas to a wide range of professionals. In this regard, training presentation skills becomes relevant for the training of specialists in higher educational institutions. The presentation has long been not only a form of transmission of lecture materials by university teachers, but is also used in various classes to control knowledge or for oral presentation of material prepared by students on their own. The presentation of information by students is most often formal in nature, since there is no prior training in the art of presenting material in the form of a presentation, which will adversely affect their future professional activities as a future teacher.

\section{Materials AND METhodS}

There are a large number of scientific and methodological works devoted to the classification of presentations, the analysis of their tasks and goals. According to Popova, she identifies two types of presentations based on the analysis of various literary sources: intracultural for representatives of one culture and intercultural for representatives of different cultures [1]. Griban classifies presentations by purpose and subdivides them into educational, research and portfolio [2]. Educational presentations are used by teachers and lecturers for teaching and knowledge control. Research presentations contain information about scientific research and achievements. Portfolio presents information about a single person in order to get acquainted with his professional and personal achievements.

Presentation methods have undergone a number of changes - from the school board and paper posters to high-tech equipment and software. One of the most common and popular computer programs is Microsoft Office PowerPoint which allows you to successfully demonstrate text, graphic, tabular, photo and video information. In the book of Meyers and Holt, special tasks for working with the audience, planning presentation materials for various fields of science and technology, as well as developing intercultural oral communication skills were developed to develop skills for successful presentations [3]. 
(ISSN - 2752-7018)

VOLUME 02 ISSUE 01 Pages: 28-34

SJIF IMPACT FACTOR $(2021: 5 \cdot 376)$

OCLC -1276789625 METADATA IF -7.569

Presentation, as one of the interactive forms of teaching, has found wide application in foreign language classes, since it is here that the skills and abilities of verbal intercultural communication are developed. According to L.A. Milovanova [4], one of the main components of a presentation culture and successful oral presentation is communication and listening skills. The presentation can be the goal of training and a means of developing the skills and abilities of speech communication. In order to be successful, the following factors are required:

- development of skills and abilities of monologue speech;

- development of skills in the use of foreign speech;

- formation of knowledge of the structure and features of individual components of the presentation.

Based on the skills acquired in the lesson, the undergraduate determines the content of the scientific presentation, which, as a rule, has the following structure:

1. Introduction (Introduction).
2. The main part of the presentation (Main body).

3. Conclusion.

This structure is generally accepted, as it allows the audience to better understand the main ideas of the project.

In the introductory part of the presentation, the speaker should greet the audience, introduce himself, his project and briefly list the main tasks of the project and explain to the audience what will be discussed.

The beginning of the presentation should be bright, memorable and planned in such a way as to attract the audience to the report and help the speaker adapt to the listeners, thereby setting the tone for a successful presentation.

The first page of the presentation is usually devoted to the title of the report, the presentation of the speaker and the team. It is very important to choose the right name for a project. It should be brief and reflect the main idea of the project in order to be understandable to the audience and at the same time to interest it from the first minutes of the presentation. 
(ISSN - 2752-7018)

VOLUME 02 ISSUE 01 Pages: 28-34

SJIF IMPACT FACTOR $(2021: 5 \cdot 376)$

OCLC -1276789625 METADATA IF -7.569

In order to make a good presentation easier, it is necessary to use visual techniques: pictures, graphs, tables, diagrams and flowcharts. The less text on the slides, the more successful the oral presentation will be. When preparing this part of the presentation, it is necessary to take into account the temporal characteristics of the presentation of information, since a prolonged report will lead to a loss of audience interest and, ultimately, to the collapse of the entire presentation.

To present a report in English, the student must know the stylistic and grammatical rules for providing graphical and tabular information, be able to describe the process what they have done.

In the final part of the presentation (Conclusion), it is necessary to summarize the entire project that has already been presented, and briefly, in the thesis form, repeat the main points and achievements. In this part of the presentation, you cannot repeat the same idea many times, you cannot start describing the project again, you cannot introduce new ideas and start describing them.

\section{PROJECT WORK}

Students will be involved in student-centred project work done in small groups. The project will be planned, discussed, and later evaluated.

\section{The project work involves three stages:}

1. Classroom planning (discussing the content and scope of the project).

2. Carrying out the project (conducting interviews, gathering materials, making recordings).

3. Reviewing and monitoring the work (discussions and feedback sessions, group analysis of the work, selfmonitoring by the participants).

The percentage to be allocated to each criterion is determined by a teacher according to the content and scope of the project, and the specifications can be modified to cater for the project content, Ss' level, institutional requirements and others.

Sample of Project Work "Our Book of People"

The project "Our Book of People" requires the following procedures: 
(ISSN - 2752-7018)

VOLUME 02 ISSUE 01 Pages: 28-34

SJIF IMPACT FACTOR $(2021: 5 \cdot 376)$

OCLC -1276789625 METADATA IF -7.569

- In groups of 3-4 select people who will be described in your book and make a list of things about them

- Use books, newspaper/magazine articles, or the Internet to come up with a list of facts/illustrations about them.

- Go through the list and choose the most interesting facts/illustrations in your groups.

- $\quad$ Take the agreed facts/illustrations and write them in your book.

- When books are ready, present them in the class

Your work will be assessed according to the following criteria:

1. Process-oriented $10 \%$

- Contribution to the process (teamwork, research skills,etc)

- Language used in the process (negotiation, interaction, interim products e.g. questionnaires) etc

2. Product-oriented $15 \%$
- Task response (focused on topic, use of resources; relevant and well supported by evidence of research)

- Language (in the outputs, e.g. presentation, brochures, posters etc)

- Organisation and delivery (a logical organisational structure)

- Design (creativity, layout, format, attractiveness) [5]

In the modern world, young people prefer comfortable clothes and forget about the formal style required when presenting a report. The teacher should remind about this and explain the importance and necessity of a neat and strict appearance.

Students should not be allowed to read the prepared text during the presentation. Of course, excitement can cause the speaker to forget the text. In this case, it is good to have small pieces of paper with the theses of the main text or use the slides of the presentation as a guide to the entire report. 
(ISSN - 2752-7018)

VOLUME 02 ISSUE 01 Pages: 28-34

SJIF IMPACT FACTOR (2021: 5 • 376)

OCLC -1276789625 METADATA IF -7.569

When choosing a presentation topic, you need to know the project very well. This will help the presenter successfully answer the questions that follow at the end of the presentation.

To present a report in English, it is necessary to know and use the speech clichés corresponding to each part of the report. For example, the phrases "In the presentation, I am going to focus on ....the project" are usually used for the introduction, and "That brings me to the end of my presentation" for the conclusion. All these phrases will help color the English-language report, link all three parts of the presentation, giving it a logical and clear structure.

The most difficult stage of the presentation is its presentation. In addition to knowing the topic and speaking English, you also need to be able to present yourself and your ideas. Only great experience and frequent performances help to develop such qualities as calmness, confidence, artistry and the ability to win over the biggest skeptics who very often listen to reports. These qualities are inherent in some people from childhood. For those who do not have charisma and artistry, a large number of rehearsals and presentations with a report in front of teachers,

classmates, friends, and parents will help. It is very useful to record oral presentations on video. In this case, all errors can be seen and try to correct them. For example, it is necessary to learn how to stand correctly between the audience and the presentation board, while not obstructing part of the screen and always facing the audience. You can not gesticulate strongly, which can distract from the main topic of the report. You need to learn to speak loudly and clearly. As a rule, people do not notice these errors, and video recording will help to eliminate them and correct behavior during the presentation.

\section{Conclusion}

As presentation is becoming more and more popular and in demand in the modern world, we need to pay attention to presentation activities not only in terms of its structure, types and goals, but also in terms of developing presentation skills among students of higher educational institutions.

\section{References}


(ISSN - 2752-7018)

VOLUME 02 ISSUE 01 Pages: 28-34

SJIF IMPACT FACTOR (2021: 5. 376)

OCLC -1276789625 METADATA IF -7.569

1. Popova O.Yu. Methods of teaching foreign language presentation skills and abilities of student managers (on the material of the English language) // Almanac of modern science and education. - 2008. No. 8-1.

2. Griban O.N. Application of educational presentations in the educational process: types, stages and structure of presentations // Historical and pedagogical readings. - 2016. - No. 20-3.

3. Collen Meyers, Sheryl Holt. Success with Presentations. A Course for Non-native Speakers of English. Aspen Productions. Burnsville. MN 55337. 2002. p. 118.

4. Milovanova L.A. Teaching students the culture of presentation by means of the discipline foreign language. Theory and Methodology of Education and Training. 2012. 5(69), pp. 127-131.

5. PreSETT Curriculum 2017, UzSWLU 